\title{
DEKAK-DEKAK GEOMETRI, MEDIA PEMBELAJARAN UNTUK MENGENALKAN BENTUK GEOMETRI PADA ANAK KELOMPOK A
}

\author{
Mahda Novita Hapsari ${ }^{1}$, Baiq Shofa Ilhami ${ }^{2}$, Yulia Agustina $^{3}$ \\ TK PKK Mayang Nira, Universitas Hamzanwadi ${ }^{2}$, Universitas Hamzanwadi ${ }^{3}$ \\ $\underline{\text { mahdanovita0@gmail.com }}^{1}$, shofa.ilhami@gmail.com $^{2}$, rahestin@ gmail.com $^{3}$
}

\begin{abstract}
Abstrak
Penelitian ini bertujuan untuk menghasilkan media pembelajaran dekak-dekak geometri untuk mengenalkan bentuk-bentuk geometri pada anak kelompok A yang direalisasikan menjadi bentuk produk berupa media dekak-dekak geometri. Penelitian pengembangan ini menggunakan model pengembangan Borg and Gall yang dilakukan dengan lima tahapan, yaitu tahap analisis kebutuhan, tahap pengembangan dan analisis produk, tahap revisi produk, tahap uji coba lapangan, dan tahap revisi produk akhir. Hasil penelitian ini menunjukkan bahwa produk yang dikembangkan berupa media dekak-dekak geometri dapat dikatakan layak digunakan dalam pembelajaran. Berdasarkan hasil validasi ahli media diperoleh data bahwa produk media dekak-dekak geometri dapat dikategorikan "baik" dengan jumlah skor 38 pada rentang skor 37, $398<\mathrm{X} \leq 46,194$. Sedangkan hasil validasi ahli materi dapat diketahui bahwa produk yang dikembangkan mendapat kategori "cukup baik" dengan jumlah skor 30 berada pada rentang 26,04 $<\mathrm{X} \leq 33,96$. Berdasarkan hasil uji coba lapangan diperoleh data siswa yang mendapat kriteria Sangat Baik sebanyak 9 orang, siswa yang mendapat kriteria Baik sebanyak 5 orang, siswa yang mendapat kriteria Cukup sebanyak 1 orang, dan siswa yang mendapat kriteria kurang sebanyak 2 orang. Data aktivitas siswa menunjukkan bahwa aktivitas belajar siswa termasuk dalam kategori "aktif" dengan skoe rata-rata 46,411. Berdasarkan hasil penelitian tersebut dapat disimpulkan bahwa produk pengembangan media dekak-dekak geometri untuk mengenalkan bentuk geometri pada anak layak digunakan dalam pembelajaran di sekolah.
\end{abstract}

Kata kunci: $\quad$ Dekak-Dekak; geometri; Kelompok A; Media Pembelajaran;

\begin{abstract}
This study aims to produce a learning media Dekak-Dekak Geometric to introduce geometric shapes in group A TK Islam Assa'adah NW Kelayu developmental. This development research used the Borg and Gall development model which is carried out in five stages, the needs analysis, the product development and analysis, the product revision, the field testing phase, and the final product revision. The results of this study indicate that the product developed, dekak-dekak geometry was suitable for learning process. Based on the results of the validation of media, dekak-dekak geometry categorized as "good" with a total score of 38 in the range of scores $37.398<\mathrm{X} \leq 46.194$. While the results of material expert validation got the category of "pretty good" with a total score of 30 in the range of $26.04<\mathrm{X} \leq 33.96$. Based on the results of field trials obtained data of students who get Very Good criteria as many as 9 people, students who get Good criteria as many as 5 people, students who get Enough criteria as many as 1 person, and students who get less criteria as many as 2 people. Student activity data shows that student learning activities are in the "active" category with an average score of 46.411. Based on the results of these studies it can be concluded that the media development products of Dekak-Dekak Geometric media to introduce geometric shapes in children are suitable for use in school learning.
\end{abstract}

Keywords: Dekak-Dekak; geometric; Group A; Instructional Media; 


\section{PENDAHULUAN}

Usia dini merupakan periode awal yang paling penting dan mendasar di sepanjang rentang pertumbuhan dan perkembangan kehidupan manusia. Ciri dari masa usia dini adalah the golden ages atau periode keemasan (Aprilianti, 2017), Pendidikan Anak Usia Dini (PAUD) pada hakikatnya adalah pendidikan yang diselenggarakan dengan tujuan untuk memfasilitasi pertumbuhan dan perkembangan anak secara menyeluruh atau menekankan pada seluruh aspek kepribadian anak. Oleh karena itu, pendidikan anak usia dini memberi kesempatan bagi siswa untuk mengembangkan kepribadian dan potensi secara maksimal dengan menyediakan berbagai aspek perkembangan seperti kognitif, bahasa, sosial, emosi, fisik, dan motorik (Suyadi, 2014: 22).

Salah satu aspek perkembangan yang perlu dikembangkan pada siswa adalah aspek perkembangan kognitif, salah satunya adalah pemahaman matematika. Konsep matematika anak usia dini berdasarkan The National Council Teachers of Mathematics(Education \& Review, 2011) tterdapat lima konsep yang dipelajari oleh anak, yaitu: bilangan dan operasi bilangan, aljabar, geometri, pengukuran, analisis data serta probabilitas. Konsep dalam matematika untuk anak usia dini yang harus dipahami oleh siswa salah satunya adalah tentang geometri.

Pengenalan geometri di TK berupa pengenalan bentuk lingkaran, segitiga, dan segiempat. Pentingnya pengenalan geometri pada siswa dimaksudkan agar siswa mampu mengenali bendabenda yang ada di sekitarnya. Dalam pertumbuhannya, anak-anak tidak dapat dipisahkan dari bendabenda yang ada di sekitarnya. Sejak kecil anak-anak sudah mengenal benda-benda terdekatnya yang bentuk bendanya sama dengan bentuk geometri, misalnya koin, lemari, meja, buku, bola, atau benda lainnya yang digunakan untuk keperluan bermain(Nilai, Anak, \& Dini, 2018)

Untuk itu, dalam proses pembelajaran yang dilakukan oleh guru harus benar-benar tepat dan bermakna untuk memperoleh hasil yang maksimal sesuai tahap perkembangan siswa. Salah satu media yang dapat digunakan guru dalam mengenalkan bentuk geometri pada siswa kelompok A adalah menggunakan Media Dekak-Dekak Geometri. Dekak-dekak adalah alat kuno untuk berhitung yang dibuat dari rangka kayu dengan sederetan poros berisi manik-manik yang bisa digeser-geserkan (Onah, 2017: 65).

Dekak-Dekak Geometri adalah dekak-dekak yang dibuat sama seperti dekak-dekak yang digunakan dalam pembelajaran matematika. Manik-maniknya diganti menggunakan bangun ruang trapesium dan pada ketiga sisinya diberi gambar lingkaran, segitiga, dan segiempat. Pada saat kegiatan pembelajaran mengenal bentuk geometri, guru dapat mengenalkan bentuk-bentuk geometri menggunakan media ini. Penggunaan media ini dalam proses pembelajaran diharapkan dapat membantu guru dalam menyampaikan materi pembelajaran kepada anak, sehingga anak dapat mengenal bentuk lingkaran, segitiga, dan segiempat.

Berdasarkan permasalah di atas maka peneliti melakukan penelitian tentang: "Pengembangan media dekak-dekak geometri untuk mengenalkan bentuk geometri pada anak kelompok A".

\section{METODOLOGI}

Jenis penelitian yang digunakan pada penelitian ini adalah penelitian dan pengembangan (Research and Development). Penelitian dang pengembangan merupakan metode penelitian yang 
digunakan untuk menghasilakan produk tertentu dan menguji keefektifan produk tersebut (Sugiyono, 2008: 297). Produk yang dikembangkan pada penelitian ini adalah media Dekak-Dekak Geometri. Model pengembangan yang digunakan merupakan adaptasi dari model pengembangan Borg and Gall. Berdasarkan kebutuhan pengembangan yang dilakukan, maka tahapan pengembangan dalam penelitian ini ada 5 tahapan yaitu: Analisis kebutuhan, Pengembangan dan validasi produk, Revisi produk,Uji coba lapangan, dan Revisi produk akhir.

Penelitian ini dilaksanakan di TK Islam Assa'adah NW Kelayu. Subyek uji coba dalam penelitian ini adalah siswa kelompok A TK Islam Assa'adah NW Kelayu yang berjumlah 17 siswa. Untuk mengukur media pembelajaran yang valid, praktis, dan efektif maka diperlukan instrumen penelitian. Instrumen penelitian yang diperlukan dala penelitian ini adalah (1) lembar validasi, (2) lembar tes hasil belajar, dan (3) lembar observasi aktivitas belajar. Data yang diperoleh dari hasil uji coba ahli dan uji coba lapangan akan dianalisis dan ditujukan untuk menjawab pertanyaanpertanyaan apakah media dekak-dekak geometri yang dikembangkan memenuhi kriteria kevalidan, kepraktisan dan keefektifan atau belum.

Untuk menentukan dan mengetahui kualitas produk, maka data kuantitatif yang didapatkan dari tim ahli dan lembar observasi aktivitas belajar siswa akan dikonversikan ke dalam data kualitatif dengan metode konversi skala lima yang diadaptasi dari Widoyoko (2009: 238).

\section{Tabel 2}

Konversi Data Kuantitatif ke Data Kualitatif dengan Skala Lima

\begin{tabular}{|c|c|c|}
\hline Nilai & Interval skor & Kategori \\
\hline A & $X>\bar{X} i+1,80 S B i$ & Sangat Baik \\
\hline B & $\bar{X} i+0,60 S B i<X \leq \bar{X} i+1,80 S B i$ & Baik \\
\hline C & $\bar{X} i-0,60 S B i<X \leq \bar{X} i+1,80 S B i$ & Cukup \\
\hline D & $\bar{X} i-1,80 S B i<X \leq \bar{X} i-0,60 S B i$ & Kurang \\
\hline E & $X \leq \bar{X} i-1,80 S B i$ & Sangat Kurang \\
\hline
\end{tabular}

Keterangan:

$\bar{X} i=$ Rerata skor ideal $=1 / 2($ skor maksimal ideal + skor minimal ideal $)$.

$S B i=$ Simpangan baku ideal $=1 / 6$ skor maksimal ideal - skor minimal ideal $)$.

$\mathrm{X}=$ Skor Aktual.

Skor tiap butir tanggapan yang diperoleh dapat dikonversikan menjadi nilai untuk mengetahui kategori secara keseluruhan terhadap hasil pengembangan. Dengan penelitian ini ditetapkan nilai kelayakan produk minimal "C", dengan kategori "cukup". Sehingga jika penilaian akhir (keseluruhan) dengan nilai minimal "C" (cukup), maka produk hasil pengembangan tersebut sudah dianggap layak digunakan.

Analisis tes hasil belajar menggunakan produk dalam proses pembelajaran.

Pengolahan data tes hasil belajar dalam penelitian ini menggunakan penilaian sebagai berikut: 1 = Belum Dapat, 2 = Kurang dapat, 3 = Dapat. Adapun rumus yang digunakan yaitu, sebagai berikut: 


$$
\mathrm{NP}=\frac{R}{S M} \times 100 \%
$$

a. Rekapitulasi Data

$$
\mathrm{P}=\frac{f}{N} \times 100 \%
$$

Keterangan:

$\mathrm{NP}=$ Nilai persen yang dicari/diharapkan

$\mathrm{R}=$ Skor mentah yang diperoleh siswa

$\mathrm{SM}=$ Skor maksimum ideal

\section{Keterangan:}

$\mathrm{P}=$ Persentase

$\mathrm{f} \quad=$ Jumlah anak yang mendapat nilai

tertentu

$\mathrm{N}=$ Jumlah seluruh anak

Tabel 3

Kriteria Keberhasilan Siswa

\begin{tabular}{|c|c|c|}
\hline No. & Interval & Kriteria \\
\hline 1 & $0-20 \%$ & Kurang Sekali \\
\hline 2 & $21-40 \%$ & Kurang \\
\hline 3 & $41-60 \%$ & Cukup \\
\hline 4 & $61-80 \%$ & Baik \\
\hline 5 & $81-100 \%$ & Sangat Baik \\
\hline
\end{tabular}

(Haryanto dkk, 2013: 19).

\section{HASIL PENELITIAN DAN PEMBAHASAN}

\section{Hasil}

Penelitian pengembangan ini telah dilakukan dengan menghasilkan produk pengembangan berupa media Dekak-Dekak Geometri. Berikut akan dijelaskan tentang hasil yang didapatkan setelah melakukan pengembangan media Dekak-Dekak Geometri. Berdasarkan Analisis Kebutuhan Data yang diperoleh dari kegiatan ini adalah: Wawancara dilakukan dengan guru kelas Kelompok A untuk mendapatkan gambaran pembelajaran yang tepat dan permasalahan yang sering dihadapi ketika pembelajaran dilaksanakan. Studi pustaka dilakukan untuk mengumpulkan materi yang diperlukan dalam menyusun produk pengembangan media Dekak-Dekak Geometri.

Data validasi ahli media terhadap produk yang dikembangkan dikonversikan menjadi data kualitatif skala lima. Dari 11 aspek indikator lima aspek yang mendapat kategori baik dan enam aspek yang mendapat kategori cukup baik. Sehingga diperoleh skor aktual 38 dan skor rata-rata 3,45. Berdasarkan rumus konversi data, terdapat lima kategori yang dapat dijadikan acuan pada media Dekak-Dekak Geometri, yaitu: a) X > 46, 194 (sangat baik); b) 37,398 < X $\leq$ 46,194 (baik); c) 28,602 $<\mathrm{X} \leq 37,398$ (cukup baik); d) 19,806 $<\mathrm{X} \leq 28,602$ (kurang baik); e) $\mathrm{X} \leq 19,806$ (sangat kurang). Sesuai dengan hasil validasi yang telah dilakukan, maka dapat diketahui bahwa produk berupa media dekak-Dekak Geometri dapat dikategorikan "baik" (37,398 < X $\leq 46,194)$. Sehingga dapat diketahui bahwa produk media Dekak-Dekak Geometri dengan kategori baik siap diuji cobakan.

Berdasarkan rumus tersebut, terdapat lima kategori yang dapat dijadikan acuan pada media Dekak-Dekak Geometri, yaitu: a) X $>41,88$ (sangat baik); b) 33,96 $<\mathrm{X} \leq 41,88$ (baik); c) 26,04 $<\mathrm{X}$ 
$\leq 33,96$ (cukup baik); d) 18,12 $<\mathrm{X} \leq 26,04$ (kurang baik); e) $\mathrm{X} \leq 18,12$ (sangat kurang). Berdasarkan hasil validasi yang telah dilakukan, maka dapat diketahui bahwa produk berupa media Dekak-Dekak Geometri dapat dikategorikan "cukup" $(26,04<\mathrm{X} \leq 33,96)$ sehingga dapat diketahui bahwa produk media Dekak-Dekak Geometri dengan kategori cukup baik siap diuji cobakan.

Berdasarkan hasil analisis dapat diketahui bahwa dari 17 siswa yang mengikuti tes, siswa yang mendapat kriteria Sangat Baik sebanyak 9 orang, siswa yang mendapat kriteria Baik sebanyak 5 orang, siswa yang mendapat kriteria Cukup Baik sebanyak 1 orang, dan siswa yang mendapat kriteria Kurang sebanyak 2 orang. Kriteria persentase keberhasilan belajar siswa yaitu Sangat Baik 52,94\%, Baik 29,41\%, Cukup Baik 5,88\%, dan Kurang 11,76\%. Dari hasil uji coba ini disimpulkan bahwa pembelajaran dengan mengguakan media Dekak-Dekak Geometri untuk mengenalkan bentuk geometri dapat dikatakan berhasil.

Setelah kegiatan pembelajaran selesai, guru menilai aktivitas belajar siswa terhadap media Dekak-Dekak Geometri untuk memperoleh data. Data tersebut dianalisis dan menunjukkan bahwa dari 12 indikator penilaian, jumlah seluruh skor yang didapat yaitu 789 dengan rata-rata 46,411. Data tersebut menunjukkan bahwa rata-rata siswa aktif belajar dengan media pembelajaran yang dikembangkan ini.

\section{A. Pembahasan}

Berdasarkan dari hasil penelitian selama kegiatan pembelajaran anak sudah mulai antusias untuk mengikuti pembelajaran, namun masih ada yang bersifat tak acuh dan sibuk dengan kegiatannya sendiri. Guru berusaha untuk menarik minat anak dengan cara mengeluarkan media Dekak-Dekak Geometri agar anak menjadi tertarik dan senang untuk mengikuti kegiatan pelajaran. Melihat media Dekak-Dekak Geometri anak lebih antusias dalam mengikuti pembelajaran sehingga anak yang duduk di belakang berdiri agar melihat dengan jelas apa yang dijelaskan oleh gurunya. Untuk mengantisipasi hal ini peneliti merevisi media Dekak-Dekak Geometri menjadi lebih besar agar anak melihatnya dengan jelas.

Untuk memperkuat pengetahuan anak tentang bentuk-bentuk geometri guru memberikan dua tes: tes mengelompokkan dan tes mencocokkan. Tes mengelompokkan yaitu anak menggunting gambar bentuk-bentuk geometri kemudian menempelnya pada kertas kosong sesuai dengan bentuk dan ukurannya. Bentuk-bentuk geometri diurutkan dari yang terkecil hingga yang terbesar. Pada tes ini banyak anak yang mengeluh capek saat menggunting karena banyaknya bentuk geometri yang digunting. Namun guru memberikannya semangat dengan melakukan tepuk semangat dan bernyanyi. Sedangkan tes mencocokkan yaitu anak mencocokkan bentuk geometri yang sejenis dengan cara mewarnainya.

Setelah semua tes dilakukan oleh anak, guru kemudian mengoreksi pekerjaan anak dan memberikan nilai. Nilai-nilai yang diperoleh kemudian dianalisis. Dengan data tersebut, maka dapat diketahui bahwa Media Dekak-Dekak Geometri dapat mengenalkan bentuk-bentuk geometri pada anak kelompok A.

\section{SIMPULAN DAN SARAN}




\section{Simpulan}

Berdasarkan hasil validasi yang dilakukan oleh ahli media dan ahli materi terhadap media DekakDekak Geometri yaitu layak digunakan dalam kegiatan pembelajaran. Adapun hasil validasi oleh ahli media dan ahli materi tersebut setalah dihitung menggunakan rumus skala lima diperoleh skor sebagai berikut:

Hasil validasi ahli media Dekak-Dekak Geometri yaitu jumlah skor 38 dengan rata-rata 3,45 berada pada interval 37,398 $<X \leq 46,194$ dalam kategori "baik" (layak digunakan). Hasil validasi ahli materi yaitu jumlah skor 30 dengan rata-rata 3berada pada interval 26,04<X $\leq 33,96$ dalam kategori "cukup" (layak digunakan).

Setelah dilakukan validasi ahli media dan ahli materi, selanjutnya dilakukan uji coba lapangan yaitu tes hasil belajar siswa dan observasi aktivitas belajar siswa. Dari hasil analisis dapat diketahui bahwa dari 17 siswa yang mengikuti tes, siswa yang mendapat kriteria Sangat Baik sebanyak 9 orang, siswa yang mendapat kriteria Baik sebanyak 5 orang, siswa yang mendapat kriteria Cukup Baik sebanyak 1 orang, dan siswa yang mendapat kriteria Kurang sebanyak 2 orang. Sehingga kriteria persentase keberhasilan belajar siswa yaitu Sangat Baik 52,94\%, Baik 29,41\%, Cukup Baik 5,88\%, dan Kurang $11,76 \%$. Sedangkan observasi aktivitas belajar siswa menunjukkan bahwa siswa "aktif" belajar menggunakan media Dekak-Dekak Geometri dengan jumlah seluruh skor yang didapat yaitu 789 dengan rata-rata 46,411 yang berada dalam interval $40,8<\mathrm{X} \leq 50,4$.

\section{Saran}

Guru hendaknya mengupayakan untuk selalu menggunakan berbagai variasi media ketika dalam proses pembelajaran yang diberikan, karena dengan adanya variasi media yang tepat maka anak akan lebih antusias dan termotivasi untuk aktif mengikuti kegiatan pembelajaran. Selain itu variasi dalam pembelajaran membuat guru lebih kreatif, menambah wawasan, dan mengetahui kemampuan dalam mengajar. Bagi sekolah, agar dapat melengkapi sarana dan prasarana yangdapat mendukung pembelajaran guna meningkatkan prestasi belajar anak.

\section{DAFTAR PUSTAKA}

Aprilianti, R. (2017). Meningkatkan Kemampuan Membilang Angka 1 Sampai 20 Melalui Permainan Bendera Pintar Pada Anak Usia 5-6 Tahun. Jurnal Golden Age Universitas Hamzanwadi, 02(4), 22-33.

Education, G., \& Review, L. (2011). General Education: A Literature Review, 10. Retrieved from https://www.wcu.edu/WebFiles/PDFs/GenEdLitReview_Final.pdf

Latif, Mukhtar Dkk. (2013). Orientasi Baru Pendidikan Anak Usia Dini. Jakarta: Prenadamedia 
Jurnal Golden Age

Vol. 3 No. 01, Juni 2019, Hal. 30-36

E-ISSN : 2549-7367

Nilai, M., Anak, K., \& Dini, U. (2018). E-issn : 2549-7367, 3(1), 44-58.

Trianto. (2011). Desain Pengembangan Pembelajaran Tematik. Jakarta: Kencana Prenada Media Group.

Suyadi. (2014). Teori Pembelajaran Anak Usia Dini dalam Kajian Neurosains. Bandung: PT Remaja Rosdakarya.

Onah. (2017). Peningkatan Hasil Belajar Perkalian melalui Penggunaan Sempoa pada Siswa Tunadaksa Kelas IV Di SDLB Pri Pekalongan. Jurnal Propesi Keguruan, Volume 3, Nomor 1, hal 65.

Sugiyono. (2008). Metode Penelitian Kuantitatif, Kualitatif dan R\&D. Bandung: CV. Alfabeta.

Widoyoko, Eko Putro. (2009). Evaluasi Program Pembelajaran. Yogyakarta: Pustaka Belajar.

Haryanto, Nar Dkk (2013). Statistika Pendidikan Tanggerang. Banten: Universitas Terbuka. 